\title{
Age differences in the relationships between risk factors and loss of kidney function: a general population cohort study
}

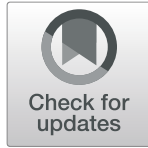

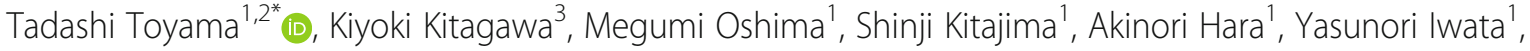
Norihiko Sakai ${ }^{1}$, Miho Shimizu ${ }^{1}$, Atsushi Hashiba ${ }^{4}$, Kengo Furuichi ${ }^{5}$ and Takashi Wada ${ }^{1}$

\begin{abstract}
Background: Annual decline in kidney function is a widely applied surrogate outcome of renal failure. It is important to understand the relationships between known risk factors and the annual decline in estimated glomerular filtration rate (eGFR) according to baseline age; however, these remain unclear.

Methods: A community-based retrospective cohort study of adults who underwent annual medical examinations between 1999 and 2013 was conducted. The participants were stratified into different age groups (40-49, 50-59, $60-69,70-79$, and $\geq 80$ years) to assess the risk for loss of kidney function. A mixed-effects model was used to estimate the association between risk factors and annual changes in eGFR.

Results: In total, 51,938 participants were included in the analysis. The age group of $\geq 80$ years included 8127 individuals. The mean annual change in eGFR was -0.39 (95\% confidence interval: -0.41 to -0.37 ) $\mathrm{mL} / \mathrm{min} / 1.73 \mathrm{~m}^{2}$ per year. Older age was related to faster loss of kidney function. In the older age group, higher systolic blood pressure, proteinuria, and current smoking were related to faster loss of kidney function ( $p$ trend $<0.01,0.03$, and $<$ 0.01 , respectively). Conversely, each age group showed similar annual loss of kidney function related to lower hemoglobin levels and diabetes mellitus ( $p$ trend 0.47 and 0.17 , respectively).

Conclusions: Higher systolic blood pressure, proteinuria, and smoking were related to faster loss of kidney function, and a greater effect size was observed in the older participants. More risk assessments for older people are required for personalized care.
\end{abstract}

Keywords: Aged, Chronic renal insufficiency, Glomerular filtration rate

\footnotetext{
* Correspondence: t-toyama@staff.kanazawa-u.ac.jp

'Department of Nephrology and Laboratory Medicine, Kanazawa University, Kanazawa, Japan

${ }^{2}$ Innovative Clinical Research Center, Kanazawa University, Kanazawa, Japan

Full list of author information is available at the end of the article
}

(c) The Author(s). 2020 Open Access This article is licensed under a Creative Commons Attribution 4.0 International License, which permits use, sharing, adaptation, distribution and reproduction in any medium or format, as long as you give appropriate credit to the original author(s) and the source, provide a link to the Creative Commons licence, and indicate if changes were made. The images or other third party material in this article are included in the article's Creative Commons licence, unless indicated otherwise in a credit line to the material. If material is not included in the article's Creative Commons licence and your intended use is not permitted by statutory regulation or exceeds the permitted use, you will need to obtain permission directly from the copyright holder. To view a copy of this licence, visit http://creativecommons.org/licenses/by/4.0/. The Creative Commons Public Domain Dedication waiver (http://creativecommons.org/publicdomain/zero/1.0/) applies to the data made available in this article, unless otherwise stated in a credit line to the data. 


\section{Background}

Chronic kidney disease (CKD) is a risk factor for cardiovascular and all-cause death, not only in middleaged people but also in older people [1-4]. Studies have revealed related risk factors, including hypertension, diabetes mellitus, or tobacco use, for the development of CKD $[5,6]$.

Older people, a major population in the efforts to prevent $C K D$ and end-stage renal disease (ESKD), have a different physiology from young and middle-aged populations, which should be considered in the treatment plan. However, knowledge of the risk factors for kidney dysfunction, particularly in older people, is sparse.

A decline in kidney function occurs with the natural physiological course of aging [7]. CKD is a common condition in older people, as nearly half of the population aged $\geq 80$ years have an estimated glomerular filtration rate (eGFR) of $\leq 60 \mathrm{~mL} / \mathrm{min} / 1.73 \mathrm{~m}^{2}$ [8]. Treatment of older people requires an integrated plan that considers these associated risks to provide them with appropriate care [7]. The increased incidence of ESKD is becoming a serious problem worldwide [9]. For example, $>28,000$ people aged $\geq 75$ years in the United States have ESKD [10]. To provide more personalized treatment for preventing age-related kidney disease, basic information about risk factors for age-associated loss of kidney function is important.

Therefore, we conducted a cohort study in the general population to examine age differences in the relationship between the comprehensively known risk factors and loss of kidney function.

\section{Methods}

\section{Study participants}

This was a community-based historical cohort study of adults who underwent annual medical examinations from 1999 to 2013 in Kanazawa City, Ishikawa Prefecture, Japan. All adults aged $\geq 40$ years were eligible to undergo medical examinations. Individuals whose serum creatinine levels were measured and who were followed up at least once during the observation period were included in the analysis. There was no upper limit of age for inclusion criteria. Individuals were excluded from the analysis if they refused to participate, lacked baseline data of covariates, or lacked follow-up eGFR data.

\section{Measurement of risk factors}

Baseline clinical parameters, including, age, sex, blood pressure, treatment of hypertension, body mass index (BMI), urinary protein, hemoglobin, total cholesterol, smoking status, history of coronary disease, and history of stroke, were recorded. Blood pressure was measured in the sitting position after a rest period. Random spot urine samples were assessed by urinary dipstick test strips, and the results were classified as negative/trace or $\geq 1+(1+$ corresponds to approximately $30 \mathrm{mg} / \mathrm{dL}$ of urine protein). eGFR was calculated from serum creatinine levels measured by enzymatic methods using the equation for Japanese people [11]. In 1999-2001, creatinine was measured using the Jaffe's reaction. From 2002, it was measured using enzymatic methods. Serum creatinine measured by the Jaffe's reaction was calibrated by subtracting $0.2 \mathrm{mg} / \mathrm{dL}$ [12]. Diabetes mellitus was defined by the following criteria: glycated hemoglobin $\geq 6.5 \%$, fasting plasma glucose $\geq 126 \mathrm{mg} / \mathrm{dL}(\geq 7.0 \mathrm{mmol} /$ L), or treatment of diabetes mellitus [13]. Information on current smoking status (regardless of smoking history), history of coronary artery disease (angina or myocardial infarction), and history of stroke (hemorrhagic or ischemic stroke) was obtained from questionnaires.

\section{Statistical analysis}

The participants were categorized into five groups according to age (40-49, 50-59, 60-69, 70-79, and $\geq 80$ years) at baseline. Analyses were conducted according to the age-stratified groups. Continuous variables are presented as mean and standard deviation, whereas categorical variables are presented as proportions. Linear trends in baseline characteristics were tested between the age categories using linear or logistic regression analysis, appropriately.

The outcome of this study was the eGFR slope represented by annual changes in eGFR $\left(\mathrm{mL} / \mathrm{min} / 1.73 \mathrm{~m}^{2}\right.$ per year) during the follow-up period. To estimate annual changes in eGFR in each individual, a mixed-effects model with a random intercept and a random slope was applied $[14,15]$. Covariates used in adjustment were selected according to previous reports on risk factors for kidney dysfunction [5, 16-19]. Baseline risk factors (covariates) included: age, sex, systolic blood pressure, diastolic blood pressure, proteinuria, hemoglobin, total cholesterol, current smoking status, history of coronary disease, history of stroke, and diabetes mellitus. Similarly, covariate-time interaction terms were used as covariates. To consider underlying risks related to blood pressure, values of 10 and $5 \mathrm{mmHg}$ were constantly added to systolic and diastolic blood pressure, respectively, in participants treated for hypertension [20, 21]. Adjusted means and 95\% confidence intervals (CIs) for annual changes in eGFR were estimated. Weighted linear regression analysis with inverse variance weighting was used to test linear trends between the mean ages of each age group and the estimated annual changes in eGFR [22].

The two-tailed significance level was set at $p<0.05$, and all analyses were performed using Stata/MP statistical software (version 14.2; StataCorp LP, College Station, TX, USA). 


\section{Results}

Selection of participants and baseline characteristics Of 133,925 individuals who underwent a medical examination in Kanazawa City between 1999 and 2013, 51, 938 met the eligibility criteria and were included in the analysis (Supplementary Figure 1). The median followup period was 4.0 years.

Table 1 shows the participants' baseline characteristics. The group with the highest number of participants was the $60-69$ years age group $(n=19,015)$. Lower eGFR and higher blood pressure were observed in the older group, and more than half of the participants aged $\geq 70$ years were treated for hypertension. Nearly half of the participants $(49 \%)$ in the age group of $\geq 80$ years had an eGFR of $<60 \mathrm{~mL} / \mathrm{min} / 1.73 \mathrm{~m}^{2}$. All groups showed quite similar levels of hemoglobin, BMI, and total cholesterol. Diabetes mellitus, history of coronary artery disease, and history of stroke were more frequent in older people than in younger people. The proportion of current smokers was the highest in the youngest group (26\%).

\section{Slope of eGFR and relationships between risk factors}

The adjusted mean eGFR slope in all participants was $0.39 \mathrm{~mL} / \mathrm{min} / 1.73 \mathrm{~m}^{2}$ per year. Significant declines in kidney function were observed in the $\geq 60$ years age groups (Table 2). Most of the known risk factors were
Table 2 Adjusted mean slope according to age groups

\begin{tabular}{lllll}
\hline Age (years) & & \multicolumn{2}{l}{$\begin{array}{l}\text { Adjusted mean slope }^{\mathbf{a}} \\
\left(\mathbf{m L} / \mathbf{m i n} / \mathbf{1 . 7 3} \mathbf{~ m}^{\mathbf{2}} \text { per year }\right)\end{array}$} & -value \\
\hline All participants & $(n=51,938)$ & -0.39 & $(-0.41,-0.37)$ & $<0.01$ \\
$40-49$ & $(n=1775)$ & 0.02 & $(-0.12,0.16)$ & 0.82 \\
$50-59$ & $(n=4386)$ & -0.01 & $(-0.08,0.07)$ & 0.86 \\
$60-69$ & $(n=19,015)$ & -0.16 & $(-0.19,-0.13)$ & $<0.01$ \\
$70-79$ & $(n=18,635)$ & -0.53 & $(-0.56,-0.49)$ & $<0.01$ \\
$\geq 80$ & $(n=8127)$ & -0.87 & $(-0.94,-0.80)$ & $<0.01$ \\
\hline
\end{tabular}

Data are presented as mean and $95 \%$ confidence interval

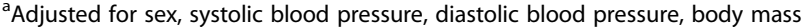
index, proteinuria, hemoglobin, total cholesterol, smoking status, history of coronary disease, history of stroke, and diabetes mellitus

associated with a significantly faster decline in eGFR, except for higher total cholesterol, which was related to a slower decline in eGFR (Table 3). Proteinuria, current smoking, and diabetes mellitus were associated with a greater decline in eGFR $(-0.58$ [95\% CI: $-0.67,-49$ ], 0.25 [95\% CI: $-0.32,-0.18$ ] , and -0.33 [95\% CI: -0.40 , - 0.26] $\mathrm{mL} / \mathrm{min} / 1.73 \mathrm{~m}^{2}$ per year, respectively). Similarly, Higher systolic blood pressure $(+10 \mathrm{mmHg})$ and lower hemoglobin $(-1 \mathrm{~g} / \mathrm{dL})$ were associated with a greater decline in eGFR $(-0.16$ [95\% CI: $-0.17,-0.14]$ and -0.16 [95\% CI: $-0.18,-0.15] \mathrm{mL} / \mathrm{min} / 1.73 \mathrm{~m}^{2}$ per year, respectively).

Table 1 Baseline characteristics of study population

\begin{tabular}{|c|c|c|c|c|c|c|c|}
\hline \multirow[b]{2}{*}{ Variable } & \multirow[b]{2}{*}{$\begin{array}{l}40-49 \\
(n=1775)\end{array}$} & \multirow[b]{2}{*}{$\begin{array}{l}50-59 \\
(n=4386)\end{array}$} & \multicolumn{3}{|l|}{ Age (years) } & \multirow[b]{2}{*}{$\begin{array}{l}\text { Overall } \\
(n=51,938)\end{array}$} & \multirow[b]{2}{*}{$p$ trend } \\
\hline & & & $\begin{array}{l}60-69 \\
(n=19,015)\end{array}$ & $\begin{array}{l}70-79 \\
(n=18,635)\end{array}$ & $\begin{array}{l}80- \\
(n=8127)\end{array}$ & & \\
\hline Age (years) & $45 \pm 3$ & $57 \pm 3$ & $65 \pm 3$ & $75 \pm 3$ & $85 \pm 4$ & $70 \pm 10$ & $<0.01$ \\
\hline Sex (men) & $34 \%$ & $32 \%$ & $39 \%$ & $39 \%$ & $33 \%$ & $37 \%$ & 0.71 \\
\hline $\mathrm{eGFR}\left(\mathrm{mL} / \mathrm{min} / 1.73 \mathrm{~m}^{2}\right)$ & $86 \pm 15$ & $79 \pm 14$ & $75 \pm 14$ & $69 \pm 15$ & $61 \pm 17$ & $72 \pm 16$ & $<0.01$ \\
\hline $\mathrm{eGFR}<60 \mathrm{~mL} / \mathrm{min} / 1.73 \mathrm{~m}^{2}$ & $2 \%$ & $6 \%$ & $12 \%$ & $25 \%$ & $49 \%$ & $22 \%$ & $<0.01$ \\
\hline eGFR $<60 \mathrm{~mL} / \mathrm{min} / 1.73 \mathrm{~m}^{2}$ and/or proteinuria $(\geq 1+)$ & $7 \%$ & $11 \%$ & $17 \%$ & $29 \%$ & $53 \%$ & $26 \%$ & $<0.01$ \\
\hline Systolic blood pressure (mmHg) & $118 \pm 17$ & $127 \pm 18$ & $132 \pm 18$ & $136 \pm 17$ & $139 \pm 18$ & $134 \pm 18$ & $<0.01$ \\
\hline Diastolic blood pressure $(\mathrm{mmHg})$ & $73 \pm 12$ & $78 \pm 12$ & $79 \pm 11$ & $77 \pm 10$ & $75 \pm 11$ & $77 \pm 11$ & $<0.01$ \\
\hline Hemoglobin (g/dL) & $13.5 \pm 1.7$ & $13.7 \pm 1.4$ & $13.7 \pm 1.3$ & $13.2 \pm 1.4$ & $12.4 \pm 1.4$ & $13.3 \pm 1.4$ & $<0.01$ \\
\hline Body mass index $\left(\mathrm{kg} / \mathrm{m}^{2}\right)$ & $22.3 \pm 3.7$ & $22.7 \pm 3.4$ & $22.9 \pm 3.1$ & $23.2 \pm 3.2$ & $22.5 \pm 3.4$ & $22.9 \pm 3.3$ & 0.01 \\
\hline Total cholesterol (mg/dL) & $201 \pm 34$ & $214 \pm 36$ & $209 \pm 34$ & $201 \pm 33$ & $195 \pm 33$ & $204 \pm 34$ & $<0.01$ \\
\hline Proteinuria $(\geq 1+)$ & $5 \%$ & $5 \%$ & $6 \%$ & $7 \%$ & $11 \%$ & $7 \%$ & $<0.01$ \\
\hline Diabetes mellitus & $2 \%$ & $7 \%$ & $10 \%$ & $13 \%$ & $12 \%$ & $11 \%$ & $<0.01$ \\
\hline Current smoker & $26 \%$ & $19 \%$ & $14 \%$ & $10 \%$ & $5 \%$ & $12 \%$ & $<0.01$ \\
\hline Treatment of hypertension (\%) & $7 \%$ & $22 \%$ & $36 \%$ & $51 \%$ & $60 \%$ & $43 \%$ & $<0.01$ \\
\hline History of coronary artery disease (\%) & $2 \%$ & $4 \%$ & $9 \%$ & $16 \%$ & $26 \%$ & $13 \%$ & $<0.01$ \\
\hline History of stroke (\%) & $1 \%$ & $3 \%$ & $5 \%$ & $9 \%$ & $13 \%$ & $7 \%$ & $<0.01$ \\
\hline Follow-up period (years) & $2.8(1.1,4.0)$ & $3.2(1.8,4.9)$ & $4.0(2.1,4.9)$ & $4.2(2.8,5.0)$ & $3.3(2.0,4.9)$ & $4.0(2.1,4.9)$ & $<0.01$ \\
\hline Number of creatinine measurements (n) & $3(2,4)$ & $3(2,5)$ & $4(3,6)$ & $5(3,6)$ & $4(2,5)$ & $4(3,6)$ & $<0.01$ \\
\hline
\end{tabular}

Continuous variables are expressed as mean \pm standard deviation, or median (25th and 75 th percentiles). Categorical variables are expressed as numbers (percentage)

Abbreviation: eGFR estimated glomerular filtration rate 
Table 3 Differences from mean slope according to risk factors

\begin{tabular}{llll}
\hline Variables & Difference from mean slope ${ }^{\text {a }}\left(\mathbf{m L} / \mathbf{m i n} / \mathbf{1 . 7 3} \mathbf{~ m}^{\mathbf{2}}\right.$ per year) & $\boldsymbol{p}$-value \\
\hline Men (vs. Women) & -0.18 & $(-0.24,-0.13)$ & $<0.01$ \\
Systolic blood pressure $(+10 \mathrm{mmHg})$ & -0.16 & $(-0.17,-0.14)$ & $<0.01$ \\
Diastolic blood pressure $(+5 \mathrm{mmHg})$ & 0.04 & $(0.02,0.05)$ & $<0.01$ \\
Body mass index (+ 1) & -0.02 & $(-0.02,-0.01)$ & $<0.01$ \\
Proteinuria 1+ (vs. normal/trace) & -0.58 & $(-0.67,-0.49)$ & $<0.01$ \\
Hemoglobin (-1 g/dL) & -0.16 & $(-0.18,-0.15)$ & $<0.01$ \\
Total cholesterol (+ 10 mg/dL) & 0.02 & $(0.01,0.03)$ & $<0.01$ \\
Current smoking (vs. no current smoking) & -0.25 & $(-0.32,-0.18)$ & $<0.01$ \\
History of coronary disease (vs. no history) & -0.15 & $(-0.21,-0.08)$ & $<0.01$ \\
History of stroke (vs. no history) & -0.10 & $(-0.19,-0.01)$ & 0.02 \\
Diabetes mellitus (vs. no diabetes) & -0.33 & $(-0.40,-0.26)$ & $<0.01$ \\
\hline
\end{tabular}

$n=51,938$. Data are presented as mean and $95 \%$ confidence interval

a Values are differences from the adjusted mean slope of all participants $(n=51,938)$. Each variable was adjusted for all other variables

\section{Slope of eGFR according to age groups}

The differences in eGFR decline according to the age group for each risk factor are shown in Fig. 1. Higher systolic blood pressure, proteinuria, and current smoking status were related to a faster decline in eGFR in the older age groups ( $p$ trend $<0.01,0.03$, and $<0.01$, respectively). Lower hemoglobin and diabetes mellitus status were related to a significantly greater eGFR decline in each age group, except for the youngest age group (age 40-49 years), and no significant trends, according to the age group, were observed ( $p$ trend 0.47 and 0.17 , respectively).

The representative estimated eGFR slopes according to age groups and risk factors (hypertension, proteinuria, and smoking status) are shown in Fig. 2. The participants without any risks (systolic blood pressure $120 \mathrm{mmHg}$, negative or trace urinary protein, and without current smoking) had almost the same mean eGFR slopes among the age groups. In a stepwise analysis of additional risks, more differences in eGFR slope according to age groups were observed.

For further trend analysis, systolic blood pressure was classified into seven categories $(<110,110-119,120$ 129, 130-139, 140-149, 150-159, and $\geq 160 \mathrm{mmHg}$ ). Higher systolic blood pressure was associated with an evidently faster decline in eGFR in the $\geq 60$ years age groups. U-shaped associations were not observed in any age group (Supplementary Figure 2).

Similar results were obtained in sensitivity analyses using systolic and diastolic blood pressure without constant addition according to the treatment status at the time of measurement (Supplementary Figure 3) and in analyses (combining participants in the 40-49 years and 50-59 years age groups) (Supplementary Figure 4).

\section{Discussion}

In this community-based longitudinal study of adults, the risks related to a faster decline in eGFR were different among age groups. In relation to hypertension, proteinuria, and smoking status, faster declines in eGFR were observed in the older group. Other risk factors, including anemia and diabetes mellitus, were related to a similar rate of eGFR decline among the age groups.

Age is one of the most fundamental considerations for providing personalized care. The risk factors for kidney dysfunction have been evaluated in cohort studies or interventional trials $[5,23]$. For example, a study of a general Japanese population showed that the relationship between blood pressure and GFR slopes varied across age groups [24]. However, age-adjusted risks, rather than age-stratified risks, have usually been evaluated, and thus, reported risk factors are limited. To achieve more personalized care, we conducted an age-stratified risk assessment of comprehensive risk factors for loss of kidney function.

\section{Clinical significance and study implications}

In this study, higher systolic blood pressure was related to a faster loss of kidney function in older people. This result was consistent with those of previous studies reporting that the absence of hypertension was related to a slower progression of kidney disease in older people $[24,25]$. A possible mechanism underlying this association might be glomerular hypertension by hyalinization of afferent arterioles [26] that may affect the autoregulation of glomerular blood flow [27]. Because active treatment of hypertension is a risk factor for kidney failure [28], a study of renal outcome regarding hypertension treatment in older people is required to evaluate the balanced target of blood pressure treatment in older people. 


\begin{tabular}{cc} 
Variables & $\begin{array}{c}\text { Age } \\
\text { (years) }\end{array}$ \\
\hline Men (vs. women) \\
$40-49$ \\
$50-59$ \\
$60-69$ \\
$70-79$ \\
$\geq 80$ \\
\\
Systolic blood pressur \\
$40-49$ \\
$50-59$ \\
$60-69$ \\
$70-79$ \\
$\geq 80$ \\
\\
Diastolic blood pressu \\
$40-49$ \\
$50-59$ \\
$60-69$ \\
$70-79$ \\
$\geq 80$ \\
\\
Body mass index (+1) \\
$40-49$ \\
$50-59$ \\
$60-69$ \\
$70-79$ \\
$\geq 80$
\end{tabular}

Proteinuria $\geq 1+$ (vs. - , trace)

$40-49$

$50-59$

$60-69$

$70-79$

Hemoglobin (-1 g/dL)

$40-49$

$50-59$

$60-69$

$70-79$

$\geq 80$

Total cholesterol $(+10 \mathrm{mg} / \mathrm{dL})$

$40-49$

$50-59$

$60-69$

$70-79$
280

Current smoking (vs. no current smoking) $40-49$

$50-59$

$60-69$

$70-79$
$\geq 80$

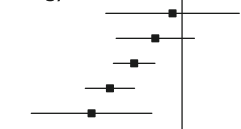

History of coronary disease (vs. no history)

$40-49$

$50-59$

$50-59$
$60-69$

$60-69$
$70-79$

$\geq 80$

History of stroke (vs. no history)

$40-49$
$50-59$

$50-59$
$60-69$

$70-79$

$\geq 80$

Diabetes (vs. no diabetes)

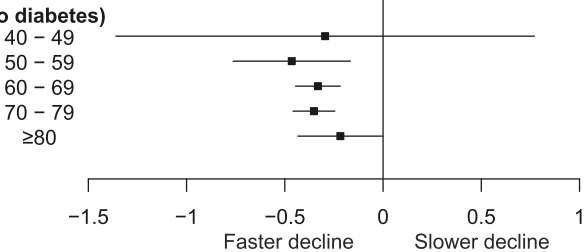

Difference from mean slope $[95 \% \mathrm{CI}]$

$\left(\mathrm{mL} / \mathrm{min} / 1.73 \mathrm{~m}^{2}\right.$ per year)

$P$ trend

$-0.24[-0.65,0.16]$

$-0.15[-0.36,0.05]$

$-0.31[-0.40,-0.22]$

$-0.12[-0.20,-0.03]$

$0.03[-0.13,0.20]$

0.22

$-0.02[-0.15,0.11]$

$-0.05[-0.12,0.01]$

$-0.10[-0.13,-0.07]$

$-0.15[-0.18,-0.13]$

$<0.01$

$-0.18[-0.22,-0.13]$

$0.00[-0.09,0.10]$

$0.00\left[\begin{array}{ll}-0.05, & 0.05]\end{array}\right.$

$0.02[0.00,0.04]$

$\left.\begin{array}{lll}0.02 & {[0.00,} & 0.04\end{array}\right]$

$-0.01[-0.05,0.03]$

0.99

$-0.01[-0.06,0.03]$

$-0.00[-0.02,0.02]$

$-0.00[-0.01,0.01]$

$-0.03[-0.04,-0.01]$

0.17

$-0.04[-0.06,-0.01]$

$0.56[-0.07,1.20]$

$-0.15[-0.49,0.18]$

$-0.51[-0.65,-0.36]$

$-0.64[-0.78,-0.50]$

$-0.74[-0.96,-0.51]$

$-0.09[-0.20,0.02]$

$-0.09[-0.16,-0.01]$

$-0.18[-0.21,-0.15]$

$-0.12[-0.15,-0.09]$

$-0.12[-0.18,-0.07]$

0.47

$0.02[-0.03,0.06]$

$0.03[0.01,0.06]$

$0.01 \quad[0.00,0.02]$

$0.01 \quad\left[\begin{array}{ll}0.00 & 0.02\end{array}\right]$

$0.02[0.00,0.04]$

0.57

$-0.05 \quad[-0.39,0.29]$

$-0.14[-0.33,0.06]$

$-0.24[-0.35,-0.14]$

$-0.37[-0.49,-0.24]$

$<0.01$

$-0.46[-0.77,-0.15]$

$-0.09[-0.98,0.80]$

$-0.15[-0.50,0.20]$

$-0.05\left[\begin{array}{ll}-0.17 & 0.07]\end{array}\right.$

$-0.08[-0.18,0.01]$

$-0.20[-0.36,-0.04]$

$0.46[-0.78,1.69]$

$0.05[-0.40,0.49]$

$-0.09[-0.25,0.07]$

$-0.07[-0.19,0.06]$

$-0.29\left[\begin{array}{lll}-1.36, & 0.77]\end{array}\right.$

$-0.46[-0.76,-0.17]$

$-0.33[-0.44,-0.22]$

$-0.35[-0.46,-0.24]$

$-0.22[-0.43,0.00]$

Fig. 1 (See legend on next page.) 
(See figure on previous page.)

Fig. 1 Risk factors for loss of kidney function and differences from the mean estimated glomerular filtration rate slopes according to age. Number of participants in each group: $n=1775$ (age 40-49 years); $n=4396$ (age 50-59years); $n=19,015$ (age 60-69 years); $n=18,635$ (age 70-79years); and $n=8127$ (age $\geq 80$ years). Values represent differences from the mean slopes of each age group. Each variable was adjusted for all other variables. The error bars represent $95 \%$ confidence intervals. The $p$ trend value was obtained to test the consistency of the age relationships among the age groups

Current smoking is a known risk factor for the loss of kidney function in middle-aged or older people [29]. Interestingly, this relationship with smoking was observed, even in the participants aged $\geq 80$ years. Current smoking was not associated with reduced kidney function in young people; however, this result should be carefully interpreted because smoking may transiently increase eGFR [30]. In addition, the elevated eGFR observed in individuals with proteinuria aged 40 to 49 years should be interpreted with caution because it may be related to single-nephron hyperfiltration [31], which could result in kidney dysfunction.

In this study, higher BMI was related to a slightly faster loss of kidney function in older people. However, no age-dependent trend was observed. Moreover, the effect sizes related to higher BMI were minimal in each age group. Considering that most participants had BMI $<30$ $\mathrm{kg} / \mathrm{m}^{2}$, this result was consistent with those of other studies that reported that a BMI of 25 to $30 \mathrm{~kg} / \mathrm{m}^{2}$ was not related to a faster loss of kidney function in any age group [32].

Interestingly, a history of stroke or coronary disease did not relate to the loss of kidney function in younger people. A study by Esposito et al. reported a faster loss of kidney function in younger people with CKD than in the elderly [33]. Considering the differences in the study design, the stable kidney function observed in younger people in our study may be because many of them had better kidney function (only $2 \%$ had an eGFR of $<60 \mathrm{ml} /$ $\min / 1.73 \mathrm{~m}^{2}$ ) and fewer complications of hypertension

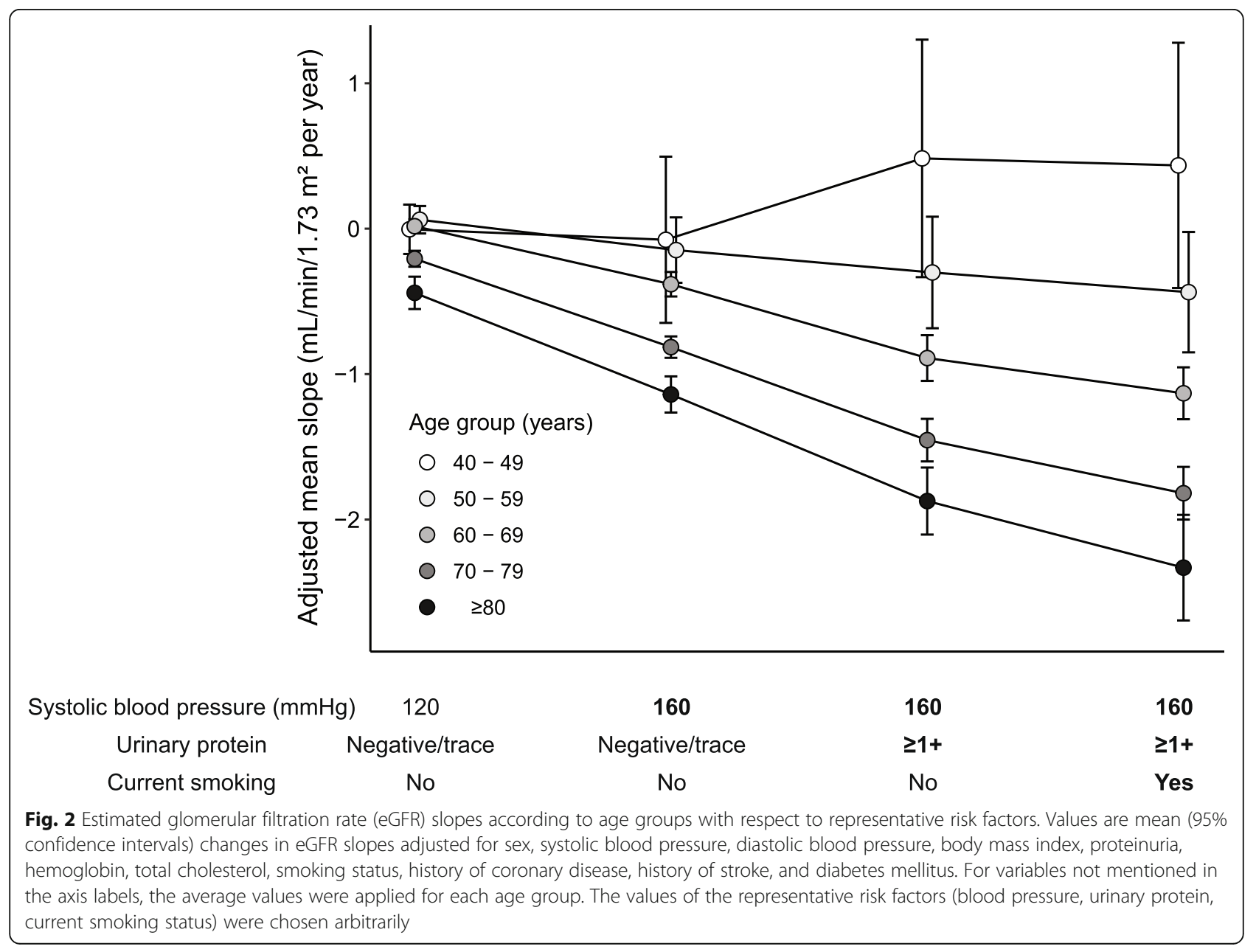


(7\%) or diabetes (2\%). Similarly, it may be because of the strict medical treatments after the event of stroke or coronary disease. In contrast, the rate of decline in kidney function in older people did not differ significantly from that in previous studies. For example, a US study reported annual rates of eGFR decline of 0.8 and $1.4 \mathrm{~mL} /$ $\mathrm{min} / 1.73 \mathrm{~m}^{2}$ in non-diabetic men and women aged 66 years and older, respectively [23].

Due to the large sample size, this study might have detected a minimal difference in the GFR slope. However, most of the significantly different risk factors observed in this study had a difference of $-0.10 \mathrm{~mL} / \mathrm{min} / 1.73 \mathrm{~m}^{2}$ from the mean slope. Considering that the mean slope was -0.39 , the presence of multiple factors could lead to a clinically significant loss of kidney function. Furthermore, risk factors that increased in association with older age might become more important over time, which is shown in Fig. 2.

\section{Strengths and limitations}

More than 50,000 Japanese people aged 40 to 80 years or older participated in this study. The participants may not be different from the typical Japanese population. The mean eGFR slope in the study population was $0.39 \mathrm{~mL} / \mathrm{min} / 1.73 \mathrm{~m}^{2}$ per year, which was almost the same as that reported in a nationwide study in Japan [24]. Furthermore, the wide range of characteristics may contribute to the generalizability of the results.

Another strength of this study was the inclusion of > 8000 participants aged $\geq 80$ years. Old-age populations are usually not stratified because of either their limited number or they are not the target population. The population of people aged $\geq 80$ years is increasing worldwide [34]. The results of this study provide basic information about the risk factors of loss of kidney function in older people. Interventional trials, including those comprising people of this age group, are warranted to validate the results of this study.

This study has several limitations. First, drug classes for the treatment of hypertension or diabetes mellitus were not considered in the analysis. Some medications, including angiotensin II receptor blockers or sodiumglucose cotransporter-2 inhibitors, may affect kidney function [35]. Second, we did not investigate the underlying diseases of kidney dysfunction that might affect the progression of the disease. Possibly, primary diseases that were not examined in this study, such as polycystic kidney disease, might have had a significant impact on renal function [36]. Furthermore, the high prevalence of kidney dysfunction and proteinuria in the elderly might indicate that the effects of disease-related treatments could not be fully adjusted. Third, smoking history was not included in the questionnaire. Because the questionnaire asked about the current smoking status at the time of examination, the risks related to smoking in older people may have been underestimated. Fourth, previous studies of kidney function have observed that annual changes in eGFR over a 3-year follow-up period can be used as a surrogate outcome for assessing the risk of ESKD, even in those with preserved kidney function [37, 38]; however, the short median follow-up period of 2.8 years in the youngest age group may affect the ability to detect changes in eGFR. Fifth, this study was not a cluster-randomized observational study, and the limited number of participants, especially those in their 40s, might have led to a selection bias toward those with health problems. Sixth, kidney dysfunction and proteinuria observed in the elderly might have been associated with all-cause and cardiovascular mortality [39], which could cause a bias towards attenuating a decline in kidney function.

\section{Conclusion}

In the general population, higher systolic blood pressure, proteinuria, and smoking status were related to greater loss of kidney function in older people. The differences in risks according to age should be considered, and interventional studies dedicated to each age group are needed to clarify the causal relationships.

\section{Supplementary Information}

The online version contains supplementary material available at https://doi. org/10.1186/s12882-020-02121-z.

Additional file 1: Figure S1. Flow diagram of the selection of study participants. Figure S2. Baseline systolic blood pressure and loss of kidney function according to age groups. Figure S3. Risk factors for loss of kidney function and differences from the mean estimated glomerular filtration rate slopes according to age (analysis using unadjusted systolic and diastolic blood pressure). Figure S4. Risk factors for loss of kidney function and differences from the mean estimated glomerular filtration rate slopes according to age (analysis of age 40-49 years merged with 50-59 years)

Abbreviations

eGFR: Estimated glomerular filtration rate; CKD: Chronic kidney disease; ESKD: End-stage renal disease; BMI: Body mass index; Cl: Confidence interval

\section{Acknowledgements}

The authors thank all the physicians and medical staffs who conducted the medical checkups in Kanazawa city, and we thank the people who participated in this study. We would like to thank Editage (www.editage.com) for English language editing.

\section{Authors' contributions}

TT and TW designed the study. TT performed the analyses, drafted the manuscript, and designed the current analysis. TT, KK, MO, SK, AH, YI, NS, MS, $\mathrm{AH}, \mathrm{KF}$ and TW review the paper and contributed to interpretation of the results. All authors read and approved the final version of the manuscript.

\section{Funding}

This work was supported by JSPS KAKENHI Grant Number: 20 K19707. The funder had no role in the study design, data collection, analysis, interpretation of data, or preparation of the manuscript. 


\section{Availability of data and materials}

The data supporting our study findings are available from Kanazawa Medical Association, but restrictions apply to the availability of these data, which were used under license for the current study, and so are not publicly available. Data are, however, available from the authors upon reasonable request and with permission of Kanazawa Medical Association.

\section{Ethics approval and consent to participate}

The study protocol was approved by the Ethics Committee of Kanazawa University (approval number 2386). Participants were provided with the opportunity to opt out of the study. If participants did not want to be included in the study, they provided written consent to be excluded. All analyses were performed using de-identified data. The study was carried out in accordance with the principles of the Declaration of Helsinki.

\section{Consent for publication}

Not Applicable.

\section{Competing interests}

None.

\section{Author details}

'Department of Nephrology and Laboratory Medicine, Kanazawa University, Kanazawa, Japan. ${ }^{2}$ Innovative Clinical Research Center, Kanazawa University, Kanazawa, Japan. ${ }^{3}$ Division of Internal Medicine, National Hospital Organization Kanazawa Medical Center, Kanazawa, Japan. ${ }^{4}$ Kanazawa Medical Association, Kanazawa, Japan. ${ }^{5}$ Department of Nephrology, Kanazawa Medical University School of Medicine, Uchinada, Japan.

Received: 15 July 2020 Accepted: 22 October 2020

Published online: 13 November 2020

\section{References}

1. Roderick PJ, Atkins RJ, Smeeth L, Mylne A, Nitsch DD, Hubbard RB, Bulpitt CJ, Fletcher AE. CKD and mortality risk in older people: a community-based population study in the United Kingdom. Am J Kidney Dis. 2009;53(6):95060.

2. Gansevoort RT, Correa-Rotter R, Hemmelgarn BR, Jafar TH, Heerspink HJL, Mann JF, Matsushita K, Wen CP. Chronic kidney disease and cardiovascular risk: epidemiology, mechanisms, and prevention. Lancet. 2013;382(9889): 339-52.

3. Stengel B, Metzger M, Froissart M, Rainfray M, Berr C, Tzourio C, Helmer C. Epidemiology and prognostic significance of chronic kidney disease in the elderly--the Three-City prospective cohort study. Nephrol Dial Transplant. 2011;26(10):3286-95

4. Hallan SI, Matsushita K, Sang Y, Mahmoodi BK, Black C, Ishani A, Kleefstra N, Naimark D, Roderick $\mathrm{P}$, Tonelli $\mathrm{M}$, et al. Age and association of kidney measures with mortality and end-stage renal disease. JAMA. 2012;308(22): 2349-60.

5. Yamagata K, Ishida K, Sairenchi T, Takahashi H, Ohba S, Shiigai T, Narita M, Koyama A. Risk factors for chronic kidney disease in a community-based population: a 10-year follow-up study. Kidney Int. 2007;71(2):159-66.

6. Haroun MK, Jaar BG, Hoffman SC, Comstock GW, Klag MJ, Coresh J. Risk factors for chronic kidney disease: a prospective study of 23,534 men and women in Washington County, Maryland. J Am Soc Nephrol. 2003;14(11): 2934-41.

7. Ellam T, Twohig H, Khwaja A. Chronic kidney disease in elderly people: disease or disease label? BMJ. 2016:352:h6559.

8. Imai E, Horio M, Watanabe T, Iseki K, Yamagata K, Hara S, Ura N, Kiyohara Y, Moriyama T, Ando $Y$, et al. Prevalence of chronic kidney disease in the Japanese general population. Clin Exp Nephrol. 2009;13(6):621-30.

9. Liyanage T, Ninomiya T, Jha V, Neal B, Patrice HM, Okpechi I, Zhao M-h, LV J, Garg AX, Knight J, et al. Worldwide access to treatment for end-stage kidney disease: a systematic review. Lancet. 2015;385(9981):1975-82.

10. 2017 USRDS ANNUAL DATA REPORT | VOLUME 2 - ESRD IN THE UNITED STATES. Chapter 1: Incidence, Prevalence, Patient Characteristics, and Treatment Modalities. Am J Kidney Dis. 2018;71(3):S247-76.

11. Matsuo S, Imai E, Horio M, Yasuda Y, Tomita K, Nitta K, Yamagata K, Tomino Y, Yokoyama H, Hishida A, et al. Revised equations for estimated GFR from serum creatinine in Japan. Am J Kidney Dis. 2009;53(6):982-92.
12. Horio M, Orita Y. Comparison of Jaffe rate assay and enzymatic method for the measurement of creatinine clearance. Jpn J Nephrol. 1996:38(7):296-9.

13. American Diabetes A. Diagnosis and classification of diabetes mellitus Diabetes Care. 2010;33(Suppl 1):S62-9.

14. Streja E, Goldstein L, Soohoo M, Obi Y, Kalantar-Zadeh K, Rhee CM. Modeling longitudinal data and its impact on survival in observational nephrology studies: tools and considerations. Nephrol Dial Transplant. 2017; 32(suppl_2):ii77-83.

15. Janmaat CJ, van Diepen M, Tsonaka R, Jager KJ, Zoccali C, Dekker FW. Pitfalls of linear regression for estimating slopes over time and how to avoid them by using linear mixed-effects models. Nephrol Dial Transplant. 2019;34(4):561-6.

16. Inaguma D, Imai E, Takeuchi A, Ohashi Y, Watanabe T, Nitta K, Akizawa T,

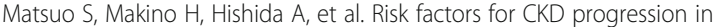
Japanese patients: findings from the chronic kidney disease Japan cohort (CKD-JAC) study. Clin Exp Nephrol. 2017:21(3):446-56.

17. Wada T, Haneda M, Furuichi K, Babazono T, Yokoyama H, Iseki K, Araki S, Ninomiya T, Hara S, Suzuki Y, et al. Clinical impact of albuminuria and glomerular filtration rate on renal and cardiovascular events, and all-cause mortality in Japanese patients with type 2 diabetes. Clin Exp Nephrol. 2014; 18(4):613-20.

18. Toyama T, Furuichi K, Ninomiya T, Shimizu M, Hara A, Iwata Y, Kaneko S, Wada T. The impacts of albuminuria and low eGFR on the risk of cardiovascular death, all-cause mortality, and renal events in diabetic patients: meta-analysis. PLoS One. 2013;8(8):e71810.

19. Hallan S, de Mutsert R, Carlsen S, Dekker FW, Aasarod K, Holmen J. Obesity, smoking, and physical inactivity as risk factors for CKD: are men more vulnerable? Am J Kidney Dis. 2006;47(3):396-405.

20. Tobin MD, Sheehan NA, Scurrah KJ, Burton PR. Adjusting for treatment effects in studies of quantitative traits: antihypertensive therapy and systolic blood pressure. Stat Med. 2005:24(19):2911-35.

21. Balakrishnan P, Beaty T, Young JH, Colantuoni E, Matsushita K. Methods to estimate underlying blood pressure: the atherosclerosis risk in communities (ARIC) study. PLoS One. 2017;12(7):e0179234.

22. Woodward M. Epidemiology: study design and data analysis, Third Edition: Taylor \& Francis; 2013

23. Hemmelgarn BR, Zhang J, Manns BJ, Tonelli M, Larsen E, Ghali WA, Southern DA, McLaughlin K, Mortis G, Culleton BF. Progression of kidney dysfunction in the community-dwelling elderly. Kidney Int. 2006;69(12):2155-61.

24. Imai E, Horio M, Yamagata K, Iseki K, Hara S, Ura N, Kiyohara Y, Makino H, Hishida A, Matsuo S. Slower decline of glomerular filtration rate in the Japanese general population: a longitudinal 10-year follow-up study. Hypertens Res. 2008;31(3):433-41.

25. El-Ghoul B, Elie C, Sqalli T, Jungers P, Daudon M, Grunfeld JP, Lesavre P, Joly D. Nonprogressive kidney dysfunction and outcomes in older adults with chronic kidney disease. J Am Geriatr Soc. 2009;57(12):2217-23.

26. Weinstein JR, Anderson S. The aging kidney: physiological changes. Adv Chronic Kidney Dis. 2010;17(4):302-7.

27. Hill GS, Heudes D, Jacquot C, Gauthier E, Bariety J. Morphometric evidence for impairment of renal autoregulation in advanced essential hypertension. Kidney Int. 2006;69(5):823-31.

28. Group SR, Wright JT Jr, Williamson JD, Whelton PK, Snyder JK, Sink KM, Rocco MV, Reboussin DM, Rahman M, Oparil S, et al. A randomized trial of intensive versus standard blood-pressure control. N Engl J Med. 2015; 373(22):2103-16

29. Shankar A, Klein $\mathrm{R}$, Klein BE. The association among smoking, heavy drinking, and chronic kidney disease. Am J Epidemiol. 2006;164(3):263-71.

30. Ishizaka N, Ishizaka Y, Toda E, Shimomura H, Koike K, Seki G, Nagai R, Yamakado M. Association between cigarette smoking and chronic kidney disease in Japanese men. Hypertens Res. 2008;31(3):485-92.

31. Melsom T, Stefansson V, Schei J, Solbu M, Jenssen T, Wilsgaard T, Eriksen $\mathrm{BO}$. Association of Increasing GFR with change in albuminuria in the general population. Clin J Am Soc Nephrol. 2016;11(12):2186-94.

32. Lu JL, Molnar MZ, Naseer A, Mikkelsen MK, Kalantar-Zadeh K, Kovesdy CP. Association of age and BMI with kidney function and mortality: a cohort study. Lancet Diab Endocrinol. 2015;3(9):704-14.

33. Esposito C, Torreggiani M, Arazzi M, Serpieri N, Scaramuzzi ML, Manini A Grosjean F, Esposito V, Catucci D, La Porta E, et al. Loss of renal function in the elderly Italians: a physiologic or pathologic process? J Gerontol A Biol Sci Med Sci. 2012;67(12):1387-93.

34. He W, Goodkind D, Kowal PR. An aging world: 2015. Washington, DC, USA: U.S. Government Publishing Office; 2016. 
35. Toyama T, Neuen BL, Jun M, Ohkuma T, Neal B, Jardine MJ, Heerspink HL, Wong MG, Ninomiya T, Wada T, et al. Effect of SGLT2 inhibitors on cardiovascular, renal and safety outcomes in patients with type 2 diabetes mellitus and chronic kidney disease: a systematic review and meta-analysis. Diabetes Obes Metab. 2019;21(5):1237-50.

36. Haynes R, Staplin N, Emberson J, Herrington WG, Tomson C, Agodoa L, Tesar V, Levin A, Lewis D, Reith C, et al. Evaluating the contribution of the cause of kidney disease to prognosis in CKD: results from the study of heart and renal protection (SHARP). Am J Kidney Dis. 2014;64(1):40-8.

37. Grams ME, Sang Y, Ballew SH, Matsushita K, Astor BC, Carrero JJ, Chang AR, Inker LA, Kenealy $\mathrm{T}$, Kovesdy $\mathrm{CP}$, et al. Evaluating glomerular filtration rate slope as a surrogate end point for ESKD in clinical trials: an individual participant meta-analysis of observational data. J Am Soc Nephrol. 2019; 30(9):1746-55.

38. Kanda E, Usui T, Kashihara N, Iseki C, Iseki K, Nangaku M. Importance of glomerular filtration rate change as surrogate endpoint for the future incidence of end-stage renal disease in general Japanese population: community-based cohort study. Clin Exp Nephrol. 2018;22(2):318-27.

39. Chronic Kidney Disease Prognosis C, Matsushita K, van der Velde M, Astor BC, Woodward M, Levey AS, de Jong PE, Coresh J, Gansevoort RT. Association of estimated glomerular filtration rate and albuminuria with allcause and cardiovascular mortality in general population cohorts: a collaborative meta-analysis. Lancet. 2010;375(9731):2073-81.

\section{Publisher's Note}

Springer Nature remains neutral with regard to jurisdictional claims in published maps and institutional affiliations.

Ready to submit your research? Choose BMC and benefit from:

- fast, convenient online submission

- thorough peer review by experienced researchers in your field

- rapid publication on acceptance

- support for research data, including large and complex data types

- gold Open Access which fosters wider collaboration and increased citations

- maximum visibility for your research: over $100 \mathrm{M}$ website views per year

At $\mathrm{BMC}$, research is always in progress.

Learn more biomedcentral.com/submissions 